\title{
Repeatability of swept-source optical coherence tomography retinal and choroidal thickness measurements in neovascular age- related macular degeneration
}

Daren Hanumunthadu ${ }^{1}$, Tomas llginis ${ }^{1}$, Marie Restori ${ }^{1}$, Mandeep S. Sagoo ${ }^{1,3}$, Adnan Tufail ${ }^{1}$, Kamaljit S Balaggan ${ }^{1,2}$, Praveen J Patel ${ }^{1}$

\footnotetext{
${ }^{1}$ NIHR Biomedical Research Centre at Moorfields Eye Hospital NHS Foundation Trust and UCL Institute of Ophthalmology, London, United Kingdom

${ }^{2}$ Wolverhampton and Midland Counties Eye Infirmary, Wolverhampton, United Kingdom

${ }^{3}$ Barts Health NHS Trust, London, United Kingdom
}

Correspondence and reprint requests:

Praveen J. Patel, Moorfields Eye Hospital NHS Foundation Trust, 162 City Road, London EC1V 2PD, United Kingdom. Email: Praveen.patel@moorfields.nhs.uk; Phone: +442072533411 Fax: +442076086925

\section{Subtitle: Swept-source OCT repeatability in AMD}

\section{Word Count: 2615}

\section{Key words:}

Age related macular degeneration; swept-source optical coherence tomography; repeatability; retinal thickness 


\section{SYNOPSIS}

This prospective cross-sectional study reports the repeatability of swept-source optical coherence tomography derived retinal and choroidal thickness measurements in eyes with neovascular age related macular degeneration. 
Background: The aim was to determine the intrasession repeatability of swept-source optical coherence tomography (SS-OCT) derived retinal and choroidal thickness measurements in eyes with neovascular age related macular degeneration (nAMD).

Methods: A prospective study consisting of patients with active nAMD enrolled in the Distance of Choroid Study (DOCS) at Moorfields Eye Hospital, London. Patients underwent three $12 \times 9 \mathrm{~mm}$ macular raster scans using the DRI-OCT-1 SS-OCT (Topcon Inc.) device in a single imaging session. Retinal and choroidal thicknesses were calculated for the ETDRS (Early Treatment Diabetic Retinopathy Study) macular subfields. Repeatability was calculated according to methods described by Bland and Altman.

Results: 39 eyes of 39 patients with nAMD were included with a mean ( \pm SD) age of $73.9( \pm$ 7.2) years. The mean $( \pm S D)$ retinal thickness of the central macular subfield was $225.7 \mu \mathrm{m}$ $( \pm 12.4 \mu \mathrm{m})$. The repeatability this subfield, expressed as a percentage of the mean central macular subfield thickness, was $23.2 \%$. The percentage repeatability of the other macular subfields ranged from $13.2 \%$ to $28.7 \%$. The intrasession coefficient of repeatability (CR) of choroidal thickness of the central macular subfield was $57.2 \mu \mathrm{m}$ with a mean choroidal thickness $( \pm$ SD) of $181 \mu \mathrm{m}( \pm 15.8 \mu \mathrm{m})$.

Conclusions: This study suggests that a change greater than $23.2 \%$ of retinal thickness and $57.2 \mu \mathrm{m}$ choroidal thickness in the central macular subfield is required to distinguish true clinical change from measurement variability when using the DRI-OCT-1 device to manage patients with nAMD. 


\section{Abbreviations:}

AMD - age-related macular degeneration

$\mathrm{Cl}$ - confidence interval

CNV - choroidal neovascularisation

CR - coefficient of repeatability

CV - coefficient of variation

DOCS - Distance of Choroid Study

ETDRS - Early Treatment Diabetic Retinopathy Study

nAMD - neovascular age-related macular degeneration

OCT - optical coherence tomography

RPE - retinal pigment epithelium

SD-OCT - spectral-domain optical coherence tomography

SD - standard deviation

SE - standard error

SS-OCT - swept-source optical coherence tomography

VA - visual acuity 


\section{INTRODUCTION}

Swept-source OCT (SS-OCT) is a recent development in OCT technology that has been recently introduced into clinical practice. SS-OCT utilises a tunable frequency light source that emits changing light frequencies over time measured by a photometer.[1] This, in combination with line scans averaging which improves the signal to noise ratio, leads to faster image acquisition and enhanced visualisation of retinal morphology. The DRI OCT-1 (Topcon Inc.) incorporates this technology and the use of a long wavelength light source in this device (central wavelength of $1050 \mathrm{~nm}$ ) theoretically enhances imaging of deeper structures including the choroid.[2]

Macular thickness measurements for the various Early Treatment of Diabetic Retinopathy Study (ETDRS) subfields are derived using on-board automated segmentation software (Topcon Advanced Boundary Segmentation TABS ${ }^{\mathrm{TM}}$ ).[3] Changes in macular thickness in eyes with neovascular age-related macular degeneration (nAMD) typically reflect disease activity, and this parameter has therefore become invaluable in guiding antiangiogenic treatment decisions both in clinical practice and in clinical trials.[4] Variation in the choroid may be associated with a range of macular conditions including pachychoroid and age related choroidopathy. [5, 6] OCT-derived subfoveal choroidal thickness measurements appear to be an important predictive factor in response to treatment with anti-angiogenic agents in eyes with nAMD.[7-9]. It has been suggested that the reported variation in choroidal thickness in patients with nAMD undergoing treatment with antiangiogenic agents indicates a potential role for this parameter in the assessment of disease activity and treatment response.[10]

An understanding of the repeatability of OCT-derived macular thickness measurements is important in order to differentiate true clinical change from mere measurement variability. Definition of measurement repeatability using SS-OCT is essential to fully describe the value of this technology in nAMD. The potential role of SS-OCT 
visualisation of the choroid in nAMD is being evaluated but description of thickness repeatability will help clinicians and researchers interpret clinical studies including those with anti-angiogenic agent. SS-OCT repeatability has been reported in normal subjects but there is potential for higher variability in patients with macular disease including nAMD. [11, 12]. Sources of measurement variability include, but are not limited to, automated inner and outer retinal boundary detection and segmentation errors, which are not uncommon when imaging eyes with nAMD and unstable fixation, resulting in variability in scan placement between consecutive scans.[13, 14]. This study estimates the repeatability of SS-OCT-derived retinal and choroidal thickness measurements in eyes with nAMD. 


\section{MATERIALS AND METHODS}

This study analysis forms part of the Distance of Choroid Study (DOCS). This was a prospective study evaluating the repeatability of a range of modalities imaging the posterior coats of the eye (sclera, choroid and retina). All participants provided written informed consent prior to commencement of the study. The study was approved by the local ethics committee (NRES Committee South East Coast - Surrey) and adhered to the tenet set forth in the Declaration of Helsinki.

\section{Study population}

Patients were identified from medical retina clinics at Moorfields Eye Hospital, London, United Kingdom. Subjects were eligible if aged between 50-90 years and had evidence of subfoveal CNV secondary to nAMD in at least 1 eye. Lesion size and type was assessed by fundus fluorescein angiography at presentation. If both eyes were eligible, the eye with the worse visual acuity was identified as the study eye. Subjects were required to be able to understand the nature of the study and be willing to undergo all the imaging investigations. Exclusion criteria included other causes of $\mathrm{CNV}$, media opacity precluding an adequate fundus view, previous ocular surgery (other than cataract surgery), and other significant ocular co-morbidity in the study eye. Patients with diabetes mellitus were also excluded from this study.

\section{SS-OCT imaging protocol}

After informed consent, medical history was obtained and best-corrected visual acuity (BCVA) measured. Subjects underwent three consecutive DRI-OCT-1 scans in a single imaging session by a clinical trials-certified technician. All subjects were adequately dilated prior to imaging with $1 \%$ tropicamide and $2.5 \%$ phenylephrine (Chauvin pharmaceuticals Ltd.). Each scan consisted of a $12 \times 9 \mathrm{~mm}$ raster centered on the fovea. 
Between scans, patients sat back away from the device and rested for a minimum of 1 minute. The device was regularly serviced by a manufacturer-approved engineer.

\section{Analysis of macular retinal and choroidal thickness}

Retinal and choroidal thickness measurements of the nine ETDRS macular subfields were calculated using the on-board segmentation algorithm (TABS $\left.{ }^{\mathrm{TM}}\right)$. The nine macular subfields are of $1 \mathrm{~mm}$ (centre A1), $3 \mathrm{~mm}$ (inner A2-5) and $6 \mathrm{~mm}(\mathrm{A6}-9)$ diameter centred on the fovea. The on-board segmentation algorithm defines the inner retinal boundary as the inner limiting membrane and the outer retinal boundary as the outer aspect of the retinal pigment epithelium (RPE)/Bruch's membrane complex.[3] DRI OCT-1 images were directly visualised by an independent observer for automated segmentation error of retinal layers. This was defined as instances in which the software-determined retinal boundaries clearly deviated from true anatomical inner or outer retinal boundaries over a distance of $1 \mathrm{~mm}$ or more (Figure 1). Patients were excluded if a segmentation error of greater than $1 \mathrm{~mm}$ was present in the central macular subfield (A1) in any of the three SS-OCT images taken. [15] Similarly, segmentation error of choroidal layers was defined as instances in which the software determined choroidal boundaries clearly deviated by $1 \mathrm{~mm}$ or more from the true anatomical boundaries (RPE/Bruch's membrane and choroidal-scleral interface) and patients were excluded if this occurred in the central macular subfield in any of the three SSOCT choroidal images (Figure 2). [15]

\section{Statistical analyses}

Mean and standard deviation (SD) of retinal thickness for each of the nine macular subfields were calculated using Excel (Microsoft Excel for Mac 2011). Repeatability was calculated using methods described by Bland and Altman.[16] Briefly, each variable was confirmed to be normally distributed and the SD of each group of 3 measurements was plotted against the mean of those measurements in order to determine whether any variability was even in part related to the magnitude of the measurement (Pearson's 
correlation coefficient). The intra-subject standard deviation $\left(S_{w}\right)$ was then calculated and the coefficient of repeatability (CR) was then calculated as $2 \times \sqrt{(}\left(2 \times S_{w}\right)$ or $2.77 \times S_{w}$. The width of the $95 \%$ confidence interval was calculated as $1.96 \times \mathrm{S}_{\mathrm{w}} / \sqrt{ } 2 n(m-1)$ where $\mathrm{n}=$ number of subjects and $\mathrm{m}=$ the number of repeated images, as described in previously completed analyses of CR in OCT measurements.[15] These analyses were also performed for choroidal thickness in each of the nine macular ETDRS subfields.

If a significant relationship was found, the data was transformed logarithmically and the analysis repeated.[17] The intra-subject standard deviation (Sw) of logarithmicallytransformed data was calculated. The intra-subject coefficient of variation (CV) was calculated as the inverse logarithm of the intra-subject standard deviation minus 1 (CV = Inverse $\left.\log _{10}(\mathrm{Sw})-1\right)$. The repeatability of the mean retinal thickness measurement of each macular subfield was calculated as $2.77 \times$ CV x 100\%.[18] 


\section{Subject Characteristics}

A total of 39 subjects were included in this study. Subject demographics and other characteristics are detailed in Table 1.

Table 1:

\begin{tabular}{|c|c|}
\hline Patient characteristics & \\
\hline Demographics & \\
\hline Age (years) & $73.9 \pm 7.2$ \\
\hline Gender ( $\mathrm{n} \%$, total) & \\
\hline Male & $24(61.5)$ \\
\hline Female & $15(38.5)$ \\
\hline Laterality (n, \% total) & \\
\hline Left & $18(46.2)$ \\
\hline Right & $21(53.8)$ \\
\hline Visual Acuity (ETDRS ${ }^{1}$ letter score) & $63.9 \pm 18.5$ \\
\hline Lens status ( $\mathrm{n} \%$ total) & \\
\hline Phakic & $29(74.4)$ \\
\hline Pseudophakic & $10(25.6)$ \\
\hline Lesion size (mean disc area $\pm \mathrm{SD}^{2}$ ) & $1.2 \pm 0.8$ \\
\hline Lesion type (n, \% total) & \\
\hline Classic & $16(41.0)$ \\
\hline Occult & $23(58.9)$ \\
\hline $\begin{array}{l}\text { Anti-angiogenic treatment history(over } \\
\text { previous } 6 \text { months) (n, \% total) }\end{array}$ & $37(94.9)$ \\
\hline Ranibizumab & $30(76.9)$ \\
\hline Aflibercept & $7(17.9)$ \\
\hline No previous treatment & $2(5.1)$ \\
\hline $\begin{array}{l}\text { Mean number of intravitreal injections } \\
\text { (over previous } 6 \text { months) }\end{array}$ & 2.5 \\
\hline
\end{tabular}

${ }^{1}$ ETDRS - early treatment diabetic retinopathy study

${ }^{2}$ SD - standard deviation 
Images were obtained between February 2014 and July 2014. The mean ( \pm SD) age of the subjects in the study was $73.9 \pm 7.2$ years. Twenty-four subjects were male and there were 21 right eyes. Mean $( \pm$ SD) BCVA was 63.9 ( \pm 18.5$)$ ETDRS letters. Thirtyseven $(94.9 \%)$ subjects had undergone treatment with anti-angiogenic agents within the previous 6 months.

\section{Retinal thickness measurements and repeatability}

The mean $( \pm$ SD) retinal thickness of the central macular subfield was $225.7 \mu \mathrm{m}( \pm$ $12.4 \mu \mathrm{m})$. The mean $( \pm \mathrm{SD})$ retinal thicknesses of the nine macular subfields are shown in Table 2. 
Table 2:

\begin{tabular}{|c|c|c|c|c|c|c|c|}
\hline $\begin{array}{l}\text { ETDRS } \\
\text { Macular } \\
\text { subfield }\end{array}$ & $\begin{array}{c}\text { Scan } 1 \\
\text { retinal } \\
\text { thicknes } \\
s(\mu \mathrm{m})\end{array}$ & $\begin{array}{c}\text { Scan } 2 \\
\text { retinal } \\
\text { thickness } \\
(\mu \mathrm{m})\end{array}$ & $\begin{array}{c}\text { Scan } 3 \\
\text { retinal } \\
\text { thickness } \\
(\mu \mathrm{m})\end{array}$ & $\begin{array}{c}\text { Mean retinal } \\
\text { thickness } \pm \\
\text { SD }(\mu \mathrm{m})\end{array}$ & $\begin{array}{c}\text { Difference } \\
\text { between } \\
\text { retinal } \\
\text { thickness } \\
\text { scans } \\
\text { (ANOVA) }\end{array}$ & $\begin{array}{c}\text { Coefficient } \\
\text { of } \\
\text { variation } \\
(\%)\end{array}$ & $\begin{array}{c}\text { Repeatability } \\
\text { (Percentage } \\
\text { of mean } \\
\text { retinal } \\
\text { thickness) } \\
(\%)\end{array}$ \\
\hline $\begin{array}{c}\mathrm{A} 1 \\
\text { central }\end{array}$ & 228.9 & 225.4 & 222.8 & $225.7 \pm 12.4$ & 0.827 & 8.4 & 23.2 \\
\hline $\begin{array}{l}\text { A2 inner } \\
\text { superior }\end{array}$ & 256.0 & 256.3 & 255.8 & $256.1 \pm 12.4$ & 0.889 & 10.3 & 28.7 \\
\hline $\begin{array}{l}\text { A3 inner } \\
\text { temporal }\end{array}$ & 257.0 & 261.7 & 258.4 & $259.1 \pm 10.2$ & 0.894 & 4.8 & 21.5 \\
\hline $\begin{array}{l}\text { A4 inner } \\
\text { inferior }\end{array}$ & 258.6 & 258.6 & 260.2 & $259.1 \pm 6.7$ & 0.878 & 5.2 & 14.5 \\
\hline $\begin{array}{c}\text { A5 inner } \\
\text { nasal }\end{array}$ & 256.5 & 259.7 & 262.8 & $259.4 \pm 9.9$ & 0.748 & 7.2 & 20.0 \\
\hline $\begin{array}{l}\text { A6 outer } \\
\text { superior }\end{array}$ & 248.4 & 251.6 & 251.9 & $259.7 \pm 7.8$ & 0.850 & 5.3 & 14.7 \\
\hline $\begin{array}{l}\text { A7 outer } \\
\text { temporal }\end{array}$ & 247.3 & 249.3 & 248.6 & $248.4 \pm 10.2$ & 0.881 & 6.3 & 14.4 \\
\hline $\begin{array}{l}\text { A8 outer } \\
\text { inferior }\end{array}$ & 239.5 & 239.4 & 236.4 & $238.4 \pm 6.1$ & 0.868 & 5.6 & 15.5 \\
\hline $\begin{array}{l}\text { A9 outer } \\
\text { nasal }\end{array}$ & 270.8 & 269.9 & 269.4 & $270.1 \pm 8.1$ & 0.868 & 4.8 & 13.2 \\
\hline
\end{tabular}


Supplementary Figure 1a shows the relationship between the mean of the three repeated central macular subfield retinal thickness measurements and their SD, and demonstrates a degree of association between mean thickness and variability (Pearson's product moment correlation coefficient $r=0.441 ; p=0.049$ two-tailed $t$-test). Other macular subfields showed a similar degree of association between mean retinal thickness and variability. After logarithmic data transformation, however, there was no statistically significant relationship between mean retinal thickness and SD for any of the macular subfields (central macular subfield: Pearson's product moment correlation coefficient $r=0.270 ; p=0.097$ two-tailed $t-$ test) (Supplementary Figure 1b). The percentage repeatability of the central macular subfield was $23.2 \%$. The percentage repeatability of the nine ETDRS macular subfields ranged from $13.2 \%$ to $28.7 \%$ (Table 2 ).

\section{Choroidal thickness measurements and repeatability}

Mean $( \pm S D$ ) of automated choroidal thickness of each of the nine ETDRS choroidal macular subfields is shown in Table 3. 
Table 3:

\begin{tabular}{|c|c|c|c|c|c|c|}
\hline $\begin{array}{l}\text { ETDRS Macular } \\
\text { subfield }\end{array}$ & $\begin{array}{l}\text { Scan } 1 \\
\text { choroidal } \\
\text { thickness } \\
(\mu \mathrm{m})\end{array}$ & $\begin{array}{l}\text { Scan } 2 \\
\text { choroidal } \\
\text { thickness }(\mu \mathrm{m})\end{array}$ & $\begin{array}{l}\text { Scan } 3 \\
\text { choroidal } \\
\text { thickness } \\
(\mu \mathrm{m})\end{array}$ & $\begin{array}{l}\text { Difference } \\
\text { between } \\
\text { choroidal } \\
\text { thickness scans } \\
\text { (ANOVA) }\end{array}$ & $\begin{array}{l}\text { Mean } \\
\text { choroidal } \\
\text { thickness } \pm \\
\text { SD }(\mu \mathrm{m})\end{array}$ & $\begin{array}{l}\text { Coefficient of } \\
\text { repeatability } \\
(95 \% \mathrm{Cl}) \\
(\mu \mathrm{m})\end{array}$ \\
\hline A1 central & 180.9 & 180.7 & 180.9 & 0.988 & $\begin{array}{l}180.9 \pm \\
14.7\end{array}$ & $\begin{array}{l}57.2(55.5- \\
58.8)\end{array}$ \\
\hline $\begin{array}{l}\text { A2 inner } \\
\text { superior }\end{array}$ & 180.3 & 182.3 & 188.8 & 0.866 & $\begin{array}{l}183.8 \pm \\
12.9\end{array}$ & $\begin{array}{l}55.4(53.8- \\
57.0)\end{array}$ \\
\hline $\begin{array}{l}\text { A3 inner } \\
\text { temporal }\end{array}$ & 179.2 & 182.9 & 183.8 & 0.936 & $\begin{array}{l}182.0 \pm \\
10.1\end{array}$ & $\begin{array}{l}41.9(40.7- \\
43.1)\end{array}$ \\
\hline $\begin{array}{l}\text { A4 inner } \\
\text { inferior }\end{array}$ & 158.7 & 164.2 & 163.3 & 0.934 & $\begin{array}{l}162.1 \pm \\
12.5\end{array}$ & $\begin{array}{l}53.3(51.8- \\
54.9)\end{array}$ \\
\hline $\begin{array}{l}\text { A5 inner } \\
\text { nasal }\end{array}$ & 162.9 & 166.2 & 166.7 & 0.973 & $\begin{array}{l}165.2 \pm \\
13.3\end{array}$ & $\begin{array}{l}60.3(58.5- \\
62.0)\end{array}$ \\
\hline $\begin{array}{l}\text { A6 outer } \\
\text { superior }\end{array}$ & 174.3 & 177.7 & 179.1 & 0.952 & $177.7 \pm 8.5$ & $\begin{array}{l}40.3(39.2- \\
41.5)\end{array}$ \\
\hline $\begin{array}{l}\text { A7 outer } \\
\text { temporal }\end{array}$ & 170.4 & 171.8 & 172.0 & 0.989 & $171.4 \pm 8.6$ & $\begin{array}{l}38.5(37.4- \\
39.6)\end{array}$ \\
\hline $\begin{array}{l}\text { A8 outer } \\
\text { inferior }\end{array}$ & 153.7 & 155.0 & 151.8 & 0.978 & $\begin{array}{l}153.5 \pm \\
12.1\end{array}$ & $\begin{array}{l}55.9(54.3- \\
57.5)\end{array}$ \\
\hline $\begin{array}{l}\text { A9 outer } \\
\text { nasal }\end{array}$ & 143.0 & 140.3 & 140.6 & 0.984 & $\begin{array}{l}141.3 \pm \\
13.0\end{array}$ & $\begin{array}{l}58.1(56.4- \\
61.4)\end{array}$ \\
\hline
\end{tabular}


The mean $( \pm S D)$ choroidal thickness of the central macular subfield was $181 \mu \mathrm{m}( \pm 15.8$ $\mu \mathrm{m})$. Supplementary Figure $1 \mathrm{c}$ shows the relationship between the automated mean choroidal thickness of the central macular subfield and the standard deviation of the measure. No correlation between the size of choroidal thickness measurements and the degree of variation was demonstrated (Pearson's product moment correlation coefficient $r=$ $0.038 ; p=0.820$ two-tailed t-test). Plots for the other subfields similarly demonstrated no correlation. The coefficient of repeatability $(C R)$ of choroidal thickness of the central macular subfield (A1) was $57.2 \mu \mathrm{m}((95 \% \mathrm{Cl} 55.5-58.8 \mu \mathrm{m})$. The CR of choroidal thickness of the other subfields ranged from $38.5 \mu \mathrm{m}$ to $60.3 \mu \mathrm{m}$ (Table 3 ).

\section{Automated segmentation error and visual acuity}

Manual assessment of all SS-OCT images showed that segmentation error of retinal layers in the central macular subfield in at least one SS-OCT image was present for 9 of 39 eyes (segmentation error rate 23.1\%) (Figure 1) with a revised CR of $23.0 \%$. Segmentation error of choroidal layers was present in 10 out of 39 eyes (segmentation error rate $25.6 \%$, Figure 2) with a revised CR of $47.3 \mu \mathrm{m}(45.7-$ $48.1 \mu \mathrm{m})$.

Supplementary Figure 2 shows the relationship between visual acuity measurements and the standard deviation of both repeated retina and choroidal thickness metrics of the central macular subfield demonstrating no significant relationship between visual acuity and retinal thickness (Pearson's $r=0.05, p=0.75$ paired T-test) and choroidal thickness (Pearson's $r=-0.09, p=0.59$ paired T-Test). 


\section{DISCUSSION}

OCT-derived macular thickness measurements are used to assess disease activity thereby guiding treatment decisions in clinical practice, as well as forming outcome variables in clinical trials that evaluate anti-angiogenic agents for nAMD and other macular disorders [19-21]. SS-OCT has been recently introduced into clinical practice but little is known of the repeatability of SS-OCT-derived macular thickness measurements. Understanding the repeatability of retinal thickness measurements is essential for assessment of disease activity in nAMD. As we discover that changes in choroidal morphology and thickness may be associated with macular disease, it is increasingly important to differentiate between true clinical change and measurement variability. In this study, we determined the percentage repeatability of SS-OCT-derived central subfield retinal thickness to be $23.2 \%$, indicating changes greater than $23.2 \%$ are required to support true clinical activity over simple measurement variability when using the DRI OCT-1 device. Previous studies have evaluated the repeatability of both time-domain-derived and SD-OCT-derived retinal thickness measurements in nAMD, but to our knowledge, there are no previous reports investigating the repeatability of retinal thickness measurements in eyes with nAMD using a commercially available SS-OCT-based device. [22-24]

After exclusion of patients with segmentation error in at least 1 SS-OCT scan, the revised percentage repeatability of the central macular subfield retinal thickness remained similar to the figure for the whole cohort $(23.0 \%)$. This relatively modest improvement in repeatability after excluding eyes with segmentation error suggests that segmentation error

is not a key factor contributing to measurement variability when using the DRI OCT-1 SSOCT device to image eyes with nAMD. Evaluation of the images of eyes without segmentation error but which displayed the most significant variability suggests that discrepancies in fixation stability between scans may have been important with some clear variation in ETDRS grid alignment (Supplementary Figure 3). This suggests that the addition 
of eye tracking hardware/ software to maintain more precise alignment and registration of follow-up scans could potentially improve repeatability. Several factors have been associated with variation in fixation stability including visual acuity and alteration in macular structure.[25] Reduced visual acuity changes have been particularly associated with poor fixation stability in eyes with nAMD.[26] Intriguingly, there was no significant association between visual acuity and variability of retinal and choroidal thickness measurements in our study and this would suggest that determinants of fixation stability may include factors other than high-contrast distance visual acuity in eyes with nAMD.

Evaluation of the clinical significance of SS-OCT derived choroidal thickness in patients with nAMD requires an appreciation of its measurement variability. Clinicians and researchers may elect to choose this newer technology particularly due to potentially deeper imaging penetration and its reliability in imaging deserve further scrutiny. We report an intrasession CR of the choroidal thickness of the central macular subfield using the DRIOCT-1 SS-OCT device as $57.2 \mu \mathrm{m}(95 \% \mathrm{Cl} 55.5-58.8 \mu \mathrm{m})$. This suggests that a change in central subfield choroidal thickness of more than $57.2 \mu \mathrm{m}$ is necessary to suggest true clinical change rather than measurement variability in eyes with nAMD. The intrasession CRs of the choroidal thickness of the other macular subfields range from $38.5 \mu \mathrm{m}$ to 60.3 $\mu \mathrm{m}$. To our knowledge, this is the first study reporting repeatability of SS-OCT derived choroidal thickness measurements in nAMD. Previous studies have reported a higher level of reproducibility of patients when measured manually in healthy patients, including a study at our institution, which suggested a CR of $34 \mu \mathrm{m}$ using EDI spectral-domain OCT.[27] We note that our previous study investigating SD-OCT (Spectralis, Heidelberg, Heidelberg Engineering) repeatability in AMD reported a CR of $30.6 \mu \mathrm{m}$ and $34.7 \mu \mathrm{m}$ for retinal and choroidal thickness repeatability.[28] This suggests that SD-OCT may be more repeatable than macular thickness measurements taken in eyes with nAMD using SS-OCT. Whilst it appeared that segmentation error was not a significant factor in SS-OCT measurement repeatability, repeatability of SD-OCT retinal thickness measurements appeared to greatly improve after exclusion of eyes with segmentation error $(13.7 \mu \mathrm{m})$. This suggests that 
different factors underlie the variability encountered in nAMD eyes using these different imaging devices.

There are several strengths and limitations of this study. This study was prospective in nature, thereby reducing inclusion / recruitment and reporting biases. Furthermore, the inclusion criteria likely reflected a real world cohort of patients attending hospital clinics for the treatment of nAMD. This study included 3 repeated measurements with a large sample size. A potential weakness of this study is that nAMD eyes with scans with segmentation error were not excluded from this study. However, this is likely to reflect real world data sets where segmentation error is a relatively common occurrence.[14] We attempted to address this potential limitation of the study by also providing a supplementary estimate of the repeatability of the central macular subfield after exclusion of subjects who had at least 1 SS-OCT scan in which segmentation error occurred. Our analysis however was not corrected for change in fixation between scans and would likely have affected our repeatability estimates adversely. This does however also represent the real world clinical scenario arguably making our results more generalizable to a clinical setting. Retinal thickness measurements were transformed logarithmically to account for any variation associated with retinal thickness magnitude. It would be useful however to extend this study by assessment of patients with severe macular edema or atrophic change with disciform scar to assess any possible variation at extremes of macular thickness.

In summary, we report the intrasession percentage repeatability of retinal thickness of the central macular subfield as $23.2 \%$ and intrasession CR of choroidal thickness in the central subfield as $57.2 \mu \mathrm{m}$ using the DRI-OCT-1 SS-OCT. This study suggests a change of greater than $23.2 \%$ of retinal thickness and greater than $57.2 \mu \mathrm{m}$ of choroidal thickness in the central macular subfield is necessary to distinguish true clinical change from measurement variability in nAMD. 


\section{ACKNOWLEDGMENTS}

\section{Funding Statement}

This work was funded by SalutarisMD and supported by the NIHR Biomedical Research Centre at Moorfields Eye Hospital NHS Foundation Trust and UCL Institute of Ophthalmology and the NIHR Moorfields Clinical Research Facility.

\section{Competing Interest Statement}

The views expressed are those of the author(s) and not necessarily those of the NHS, the NIHR or the Department of Health.

\section{Contributorship statement}

Design and conduct of study: DH, MR, MS, AT, KB, PJP; Collection, management, analysis and interpretation of data: $\mathrm{DH}, \mathrm{TI}, \mathrm{MR}, \mathrm{KB}, \mathrm{PJP}$;

Preparation of manuscript: DH, KB, PJP. All authors gave critical review and final approval of the manuscript 


\section{REFERENCES:}

1. Adhi M, Duker, JS. Optical coherence tomography--current and future applications. Curr Opin Ophthalmol 2013;24(3):213-21 doi: 10.1097/ICU.0b013e32835f8bf8published Online First.

2. de Bruin DM, Burnes, DL, Loewenstein, J, et al. In vivo three-dimensional imaging of neovascular age-related macular degeneration using optical frequency domain imaging at $1050 \mathrm{~nm}$. Invest Ophthalmol Vis Sci 2008;49(10):4545-52 doi: 10.1167/iovs.07-1553published Online First.

3. Yang $Q$, Reisman, CA, Wang, Z, et al. Automated layer segmentation of macular OCT images using dual-scale gradient information. Opt Express 2010;18(20):21293-307 doi: 10.1364/OE.18.021293published Online First.

4. Keane PA, Liakopoulos, S, Jivrajka, RV, et al. Evaluation of optical coherence tomography retinal thickness parameters for use in clinical trials for neovascular age-related macular degeneration. Invest Ophthalmol Vis Sci 2009;50(7):3378-85 doi: 10.1167/iovs.082728published Online First.

5. Spaide RF. Age-related choroidal atrophy. Am J Ophthalmol 2009;147(5):801-10 doi: 10.1016/j.ajo.2008.12.010published Online First.

6. Gallego-Pinazo R, Dolz-Marco, R, Gomez-Ulla, F, et al. Pachychoroid diseases of the macula. Med Hypothesis Discov Innov Ophthalmol 2014;3(4):111-5 Online First: 2014/01/01].

7. Razavi S, Souied, EH, Darvizeh, F, et al. Assessment of choroidal topographic changes by swept source optical coherence tomography after intravitreal ranibizumab for exudative agerelated macular degeneration. Am J Ophthalmol 2015 doi: 10.1016/j.ajo.2015.08.009published Online First.

8. Koizumi H, Kano, M, Yamamoto, A, et al. Short-term changes in choroidal thickness after aflibercept therapy for neovascular age-related macular degeneration. Am J Ophthalmol 2015;159(4):627-33 doi: 10.1016/j.ajo.2014.12.025published Online First.

9. Kang HM, Kwon, $\mathrm{HJ}, \mathrm{Yi}, \mathrm{JH}$, et al. Subfoveal choroidal thickness as a potential predictor of visual outcome and treatment response after intravitreal ranibizumab injections for typical exudative age-related macular degeneration. Am J Ophthalmol 2014;157(5):1013-21 doi: 10.1016/j.ajo.2014.01.019published Online First.

10. Shin JY, Kwon, KY, Byeon, SH. Association between choroidal thickness and the response to intravitreal ranibizumab injection in age-related macular degeneration. Acta Ophthalmol 2015 doi: 10.1111/aos.12653published Online First.

11. Mansouri K, Medeiros, FA, Tatham, AJ, et al. Evaluation of retinal and choroidal thickness by swept-source optical coherence tomography: repeatability and assessment of artifacts. Am J Ophthalmol 2014;157(5):1022-32 doi: 10.1016/j.ajo.2014.02.008published Online First.

12. Matsuo Y, Sakamoto, T, Yamashita, T, et al. Comparisons of choroidal thickness of normal eyes obtained by two different spectral-domain OCT instruments and one swept-source OCT instrument. Invest Ophthalmol Vis Sci 2013;54(12):7630-6 doi: 10.1167/iovs.1313135published Online First.

13. Midena E, Radin, PP, Pilotto, E, et al. Fixation pattern and macular sensitivity in eyes with subfoveal choroidal neovascularization secondary to age-related macular degeneration. A microperimetry study. Seminars in ophthalmology 2004;19(1-2):55-61 doi: 10.1080/08820530490882896published Online First: 2004/12/14].

14. Kim M, Lee, SJ, Han, J, et al. Segmentation error and macular thickness measurements obtained with spectral-domain optical coherence tomography devices in neovascular age-related macular degeneration. Indian J Ophthalmol 2013;61(5):213-7 doi: 10.4103/03014738.97075published Online First. 
15. Comyn O, Heng, LZ, Ikeji, F, et al. Repeatability of Spectralis OCT measurements of macular thickness and volume in diabetic macular edema. Invest Ophthalmol Vis Sci 2012;53(12):7754-9 doi: 10.1167/iovs.12-10895published Online First.

16. Bland JM, Altman, DG. Statistical methods for assessing agreement between two methods of clinical measurement. Lancet 1986;1(8476):307-10 Online First.

17. Bland JM, Altman, DG. Measurement error proportional to the mean. BMJ 1996;313(7049):106 Online First.

18. Lodge MA, Jacene, HA, Pili, R, et al. Reproducibility of tumor blood flow quantification with 150water PET. J Nucl Med 2008;49(10):1620-7 doi: 10.2967/jnumed.108.052076published Online First.

19. Tufail A, Patel, PJ, Egan, C, et al. Bevacizumab for neovascular age related macular degeneration ( $A B C$ Trial): multicentre randomised double masked study. BMJ 2010;340:c2459 doi: 10.1136/bmj.c2459published Online First.

20. Heier JS, Brown, DM, Chong, V, et al. Intravitreal aflibercept (VEGF trap-eye) in wet age-related macular degeneration. Ophthalmology 2012;119(12):2537-48 doi: 10.1016/j.ophtha.2012.09.006published Online First.

21. Brown DM, Nguyen, QD, Marcus, DM, et al. Long-term outcomes of ranibizumab therapy for diabetic macular edema: the 36-month results from two phase III trials: RISE and RIDE. Ophthalmology 2013;120(10):2013-22 doi: 10.1016/j.ophtha.2013.02.034published Online First.

22. Tah V, Keane, PA, Esposti, SD, et al. Repeatability of retinal thickness and volume metrics in neovascular age-related macular degeneration using the Topcon 3DOCT-1000. Indian J Ophthalmol 2014;62(9):941-8 doi: 10.4103/0301-4738.143936published Online First.

23. Patel PJ, Chen, FK, Ikeji, F, et al. Intrasession repeatability of optical coherence tomography measures in active neovascular age-related macular degeneration. Acta Ophthalmol 2011;89(6):526-32 doi: 10.1111/j.1755-3768.2009.01761.xpublished Online First.

24. Parravano M, Oddone, F, Boccassini, B, et al. Reproducibility of macular thickness measurements using Cirrus SD-OCT in neovascular age-related macular degeneration. Invest Ophthalmol Vis Sci 2010;51(9):4788-91 doi: 10.1167/iovs.09-4976published Online First.

25. Mathew R, Pearce, E, Sivaprasad, S. Determinants of fixation in eyes with neovascular agerelated macular degeneration treated with intravitreal ranibizumab. Am J Ophthalmol 2012;153(3):490-96 e1 doi: 10.1016/j.ajo.2011.08.034published Online First.

26. Sivaprasad S, Pearce, E, Chong, V. Quality of fixation in eyes with neovascular age-related macular degeneration treated with ranibizumab. Eye (Lond) 2011;25(12):1612-6 doi: 10.1038/eye.2011.223published Online First.

27. Rahman W, Chen, FK, Yeoh, J, et al. Enhanced depth imaging of the choroid in patients with neovascular age-related macular degeneration treated with anti-VEGF therapy versus untreated patients. Graefe's archive for clinical and experimental ophthalmology = Albrecht von Graefes Archiv fur klinische und experimentelle Ophthalmologie 2013;251(6):1483-8 doi: 10.1007/s00417-012-2199-xpublished Online First: 2012/11/20].

28. Hanumunthadu D, Ilginis, T, Restori, M, et al. Spectral-domain optical coherence tomography retinal and choroidal thickness metric repeatability in age related macular degeneration. Am J Ophthalmol 2016 doi: 10.1016/j.ajo.2016.03.052published Online First. 


\section{FIGURE LEGENDS}

Figure 1: Examples of DRI OCT-1 swept-source optical coherence tomography images with evidence of segmentation error affecting retinal layers of the central macular subfield. The automated software-determined retinal boundaries clearly deviate away from the true anatomical inner (inner limiting membrane) or outer (outer aspect of the RPE/Bruch's membrane complex) retinal boundaries for at least $1 \mathrm{~mm}$ in a tangential plane.

Figure 2: Examples of DRI OCT-1 swept-source optical coherence tomography images with evidence of segmentation error affecting choroidal layers of the central macular subfield. The automated software-determined retinal boundaries clearly deviate away from the true anatomical inner (outer aspect of the RPE/Bruch's membrane complex)) or outer (Haller's layer) choroidal boundaries for at least $1 \mathrm{~mm}$ in a tangential plane.

Supplementary Figure 1: (A) Plot of mean and standard deviation central macula subfield (A1) thickness. There was statistically significant correlation between the mean thickness and the SD of the central macular subfield (Pearson's $r=0.441$; $p=0.049$ two-tailed t-test). (B) Plot of logarithmically transformed mean and standard deviation of central macular subfield (A1) retinal thickness. There was no statistically significant correlation when analysis was performed on logarithmically transformed data $(r=0.270 ; p=0.097$ two tailed t-test) $(C)$ Plot of mean and standard deviation of submacular choroidal thicknesss of the central macular subfield (A1). There was no statistically significant correlation between the mean choroidal thickness and the SD of the central macular subfield $(r=0.038 ; p=0.820$ two tailed $t-$ test) 
Supplementary Figure 2: Correlation between visual acuity and macular thickness variability (A)plot of visual acuity ETDRS (Early Treatment Diabetic Retinopathy) letters and standard deviation of retinal thickness repeatability measurements, Pearson's $r=0.05, p=$ 0.75 two-tailed T-Test) (B) plot of visual acuity ETDRS letters and standard deviation of choroidal thickness repeatability measurements, Pearson's $r=-0.09, p=0.59$ two-tailed TTest)

Supplementary Figure 3: Intrasession differences in software-determined ETDRS grid locations in neovascular age-related macular degeneration eyes using the DRI OCT-1 swept-source optical coherence tomography device. Three successive infrared fundus photographs with position of ETDRS grid for a patient representative of those displaying high variability in retinal thickness measurements. These images demonstrate intrasession variation in retinal thickness measurements within this eye; central macular subfield thicknesses were $191 \mu \mathrm{m}, 296 \mu \mathrm{m}$, and $294 \mu \mathrm{m}$ in scans 1,2 and 3 , respectively.

\section{TABLE LEGENDS:}

Table 1: Subject characteristics of patients with neovascular age-related macular degeneration.

Demographics (age, gender, laterality), lens status, lesion size and type and history of treatment with anti-vascular endothelial growth factor agents.

Table 2: Retinal thickness metrics and intrasession repeatability in neovascular agerelated macular degeneration 
Mean $( \pm)$ standard deviation of mean retinal thickness of Early Treatment Diabetic Retinopathy Study macular subfields in three successive scans. No significant difference in mean retinal thickness was found between the mean retinal thickness of three repeated scans (one-way ANOVA). Intrasession repeatability of retinal thickness measurements of each macular subfield are shown.

Table 3: Choroidal thickness metrics and intrasession coefficient of repeatability in neovascular age-related macular degeneration

Mean $( \pm)$ standard deviation of mean choroidal thickness of Early Treatment Diabetic Retinopathy Study submacular subfields in three successive scans. No significant difference in mean choroidal thickness was found between the mean choroidal thickness of three repeated scans (one-way ANOVA). Intrasession coefficient of repeatability of choroidal thickness measurements of each macular subfield are shown. 